

Cite this: Phys. Chem. Chem. Phys., 2016, 18, 19713

Received 26th May 2016, Accepted 22nd June 2016

DOI: $10.1039 / c 6 c p 03637 f$

www.rsc.org/pccp

\title{
Dynamics of ultrathin V-oxide layers on Rh(111) in catalytic oxidation of ammonia and $\mathrm{CO}$
}

\author{
B. von Boehn, A. Preiss $\dagger$ and R. Imbihl*
}

\begin{abstract}
Catalytic oxidation of ammonia and $\mathrm{CO}$ has been studied in the $10^{-4}$ mbar range using a catalyst prepared by depositing ultra-thin vanadium oxide layers on $\operatorname{Rh}(111)\left(\theta_{V} \approx 0.2 \mathrm{MLE}\right)$. Using photoemission electron microscopy (PEEM) as a spatially resolving method, we observe that upon heating in an atmosphere of $\mathrm{NH}_{3}$ and $\mathrm{O}_{2}$ the spatial homogeneity of the $\mathrm{VO}_{x}$ layer is removed at $800 \mathrm{~K}$ and a pattern consisting of macroscopic stripes develops; at elevated temperatures this pattern transforms into a pattern of circular $\mathrm{VO}_{x}$ islands. Under reaction conditions the neighboring $\mathrm{VO}_{x}$ islands become attracted by each other and coalesce. Similar processes of pattern formation and island coalescence are observed in catalytic CO oxidation. Reoxidation of the reduced $\mathrm{VO}_{x}$ catalyst proceeds via surface diffusion of oxygen adsorbed onto $\mathrm{Rh}(111)$. A pattern consisting of macroscopic circular $\mathrm{VO}_{x}$ islands can also be obtained by heating a $\mathrm{Rh}(111) / \mathrm{VO}_{x}$ catalyst in pure $\mathrm{O}_{2}$.
\end{abstract}

\section{Introduction}

Vanadium oxide based catalysts are the most important catalysts in the chemical industry finding applications in the partial oxidation of organic compounds, in sulfuric acid production, and in the selective catalytic reduction of $\mathrm{NO}_{\mathrm{x}}{ }^{1,2}$ The catalytic properties of $\mathrm{V}$ oxides can be attributed to the easy change of vanadium between different oxidation states, i.e. between $\mathrm{V}^{2+}$, $\mathrm{V}^{3+}, \mathrm{V}^{4+}$ and $\mathrm{V}^{5+}$. In practical catalytic applications $\mathrm{V}$ oxides are usually supported on oxides such as $\mathrm{SiO}_{2}, \mathrm{Al}_{2} \mathrm{O}_{3}$ or $\mathrm{TiO}_{2}$. The interaction with the support material can drastically change the catalytic properties of $\mathrm{V}$ oxides. The nature of this interaction and the reaction mechanisms in partial oxidation reactions have been the subject of intense research in recent years. ${ }^{2-11}$

$\mathrm{V}$ oxide in its catalytically most active form was shown to be distributed as a thin layer or as isolated $\mathrm{VO}_{x}$ clusters. ${ }^{9}$ As a model system for very thin $\mathrm{V}$ oxide catalysts one can consider ultrathin $(<2 \mathrm{~nm})$ layers of $\mathrm{V}$ oxide on a $\mathrm{Rh}(111)$ surface. In the submonolayer range $\mathrm{VO}_{x}$ on $\mathrm{Rh}(111)$ exhibits a number of wellordered 2D-phases which have been thoroughly characterized by scanning tunneling microscopy (STM), low energy electron diffraction (LEED) and X-ray photoelectron spectroscopy (XPS); supported by density functional theory (DFT) calculations structural models have been proposed for most of the 2D-phases. ${ }^{12-16}$

PEEM as a spatially resolving method demonstrated in the $10^{-4}$ mbar range that these ultrathin $\mathrm{VO}_{x}$ overlayers undergo restructuring during catalytic reactions. ${ }^{17-19}$ In the $\mathrm{O}_{2}+\mathrm{H}_{2}$

Institut für Physikalische Chemie und Elektrochemie, Leibniz Universität Hannover, Callinstrasse 3-3a, D-30167 Hannover, Germany.E-mail: imbihl@pci.uni-hannover.de $\dagger$ Present adress: Institut für Anorganische Chemie, Leibniz Universität Hannover, Callinstrasse 9, D-30167 Hannover, Germany. reaction and in the partial oxidation of methanol the initially homogeneously distributed $\mathrm{VO}_{x}$ condenses into macroscopic stripes which at elevated temperatures transform into circular islands. In catalytic methanol oxidation on $\mathrm{Rh}(111) / \mathrm{VO}_{x}$ a rather unexpected observation was made. ${ }^{19}$ It was found that the macroscopic circular $\mathrm{VO}_{x}$ islands under reaction conditions start to move towards each other when they come within a critical distance of about $100 \mu \mathrm{m}$ until they finally coalesce. This island coalescence process which leads to a coarsening of the islands similar to Ostwald ripening was explained by a chemical equilibrium between small isolated $\mathrm{V}_{n} \mathrm{O}_{m}$ clusters on the metal surface and macroscopic $\mathrm{VO}_{x}$ islands according to

$$
\left(\mathrm{V}_{2} \mathrm{O}_{3}\right)_{n}+3 m \mathrm{O} \rightleftarrows\left(\mathrm{V}_{2} \mathrm{O}_{3}\right)_{n-3 m}+m\left(\mathrm{~V}_{6} \mathrm{O}_{12}\right)
$$

Here, $\left(\mathrm{V}_{2} \mathrm{O}_{3}\right)_{n}$ represents a large $\mathrm{VO}_{x}$ island and $\mathrm{V}_{6} \mathrm{O}_{12}$ is the stoichiometry of clusters identified in a STM study. ${ }^{14,15}$ Since this polymerization/depolymerization equilibrium is controlled by the oxygen coverage, in the case of two neighboring $\mathrm{VO}_{x}$ islands, $\mathrm{VO}_{x}$ is transported from the more distant sides of the two islands where the oxygen coverage is higher to the two sides facing each other where the oxygen coverage is lower. The net result of this transport is that the two islands move closer to each other. ${ }^{19}$

The essential requirements for this mechanism to operate, the existence of an oxygen gradient around each $\mathrm{VO}_{x}$ island and of a small $\mathrm{V}$ coverage on the free metal surface reflecting the presence of small $\mathrm{V}_{n} \mathrm{O}_{m}$ clusters, are well supported by experiment. ${ }^{19}$ The island coalescence in catalytic methanol oxidation demonstrates that the $\mathrm{VO}_{x}$ distribution on a support is governed by dynamic processes but the question is of course how general this mechanism is. Does the same mechanism also hold for other reactions using $\mathrm{VO}_{x}$ as a catalyst? How does it depend on the support material and does the mechanism 
potentially also extend to other supported oxide catalysts with a similar network structure as $\mathrm{VO}_{x}$ ? The objective of this article is to verify whether we observe an island coalescence also in other reactions on the same catalyst, $\mathrm{Rh}(111) / \mathrm{VO}_{x}$. For this reason we study catalytic ammonia oxidation and catalytic CO oxidation on this catalyst. In fact, we observe an island coalescence also in these reactions but these systems exhibit a number of interesting differences to methanol oxidation which provide us with details about the underlying physical processes.

\section{Experimental}

All experiments were carried out in a standard UHV chamber equipped with a four-grid LEED optics, a cylindrical mirror analyzer for Auger electron spectroscopy (AES), a differentially pumped quadrupole mass spectrometer (QMS) to measure reaction rates and a photoemission electron microscope (PEEM) to follow in situ the spatiotemporal dynamics of the surface with a spatial resolution of about $1 \mu \mathrm{m}$ and a temporal resolution of 0.2 seconds. In PEEM the sample is illuminated by a deuterium discharge lamp (5-6 eV photon energy) and the ejected photoelectrons are collected. ${ }^{20}$ PEEM, therefore, images primarily the local work function and it provides only indirect chemical information.

The $\mathrm{Rh}(111)$ sample (diameter $8 \mathrm{~mm}$, thickness $1.5 \mathrm{~mm}$ ) can be heated either resistively by passing electric current through two Ta wires spot welded to the sample or indirectly through electron bombardment from the backside. The sample is cleaned by repeated cycles of Argon ion sputtering ( $2 \mathrm{keV}, 770 \mathrm{~K}$ ), flashing to $1370 \mathrm{~K}$, oxidation $\left(1 \times 10^{-6} \mathrm{mbar}_{2}, 1020 \mathrm{~K}, 20 \mathrm{~min}\right)$ and a final flashing to $1370 \mathrm{~K}$. Gases of purity 4.5 for oxygen, 5.0 for ammonia, and 3.7 for carbon monoxide are used. A feedback controlled gas inlet system ensures constant partial pressures during the reaction. For rate measurements the sample was placed $\approx 1-2 \mathrm{~mm}$ in front of a cone with an opening of $5 \mathrm{~mm}$ diameter which connects the main chamber with the differentially pumped QMS. In this way only molecules that have hit the sample surface can be detected by the QMS.

Ordered overlayers of $\mathrm{VO}_{x}$ on $\mathrm{Rh}(111)$ are prepared by the reactive evaporation of 0.2 monolayer equivalents (MLE) of $\mathrm{V}$ at $670 \mathrm{~K}$. The $\mathrm{V}$ coverage is obtained from the $\mathrm{V}_{473}$ Auger signal which has been calibrated using the LEED patterns of ordered $\mathrm{VO}_{x}$ phases of known composition. ${ }^{19}$ Subsequently, the $\mathrm{V}$ oxide layer is post-oxidized for additional 10 minutes. After preparation the surface displays a LEED pattern of $(\sqrt{ } 7 \times \sqrt{ } 7) R 19.1^{\circ}$ structure corresponding to an ideal coverage of $\theta_{\mathrm{V}}=0.43$ MLE. ${ }^{12,13}$ Superimposed onto the $\sqrt{ } 7$ pattern one observes a $(2 \times 2)$ of chemisorbed oxygen on $\mathrm{Rh}(111)$.

For better visibility the contrast of the presented PEEM images has been enhanced.

\section{Results}

\section{$\mathrm{NH}_{3}+\mathrm{O}_{2}$ reaction}

Starting with a $\mathrm{Rh}(111)$ surface uniformly covered with $\mathrm{VO}_{x}$ the surface is exposed to the reaction gases $\mathrm{NH}_{3}$ and $\mathrm{O}_{2}$ in the $10^{-4}$ mbar range at $300 \mathrm{~K}$ and then slowly heated up to $1020 \mathrm{~K}$ with a constant heating rate of $0.5 \mathrm{~K} \mathrm{~s}^{-1}$. The description spatially uniform refers to PEEM which means that the surface is uniform on a macroscale $(>1 \mu \mathrm{m})$. On a mesoscale, however, the $\mathrm{VO}_{x}$ layer with $\theta_{\mathrm{V}} \approx 0.2 \mathrm{MLE}$ exhibits a porous structure. ${ }^{19}$ Similar to catalytic methanol oxidation, the spatial homogeneity is removed at $\approx 800 \mathrm{~K}$. As shown in Fig. 1 first thin dark stripes form which then rapidly coarsen with increasing temperature. Since the $\mathrm{Rh}(111)$ surface is isotropic the apparent preferential orientation of the stripes is probably due to step bunches as shown in previous experiments. ${ }^{18}$

At $T \approx 1000 \mathrm{~K}$ the stripes transform into circular islands of about $100 \mu \mathrm{m}$ diameter. Using the experimental results from catalytic methanol oxidation and from the $\mathrm{O}_{2}+\mathrm{H}_{2}$ reaction, we can assign the dark areas in the PEEM images to a $\mathrm{VO}_{x}$ covered surface. ${ }^{18,19}$ Similar to methanol oxidation, the circular $\mathrm{VO}_{x}$ islands exhibit a substructure with a bright core followed by a thin dark ring and a broad outer ring of dark grey intensity. The brightness in PEEM, which reflects the local work function, does not convey any direct chemical information but it is probably safe to assume that the same qualitative relations between the grey level in PEEM and the $\mathrm{V}$ oxidation state which has been derived via $\mu$ XPS in methanol oxidation also hold for this reaction system. The bright core of the $\mathrm{VO}_{x}$ islands accordingly represents a more reduced state of $\mathrm{VO}_{x}$, e.g. $\mathrm{V}^{3+}$, and the outer ring a more oxidized state, e.g. $\mathrm{V}^{4+} / \mathrm{V}^{5+} . \ddagger^{19}$

When two $\mathrm{VO}_{x}$ islands come within a critical distance of about $100 \mu \mathrm{m}$ they start moving towards each other and finally coalesce. This process is depicted in Fig. 2. Qualitatively, the process is identical to coalescence in methanol oxidation. ${ }^{19}$ The movement of the islands accelerates as the distance between two islands shrinks and as the islands merge the elliptically distorted island initially formed rapidly transforms into a circular shape.

Fig. 3 displays the evolution of the $\mathrm{N}_{2}$, $\mathrm{NO}$ and $\mathrm{H}_{2} \mathrm{O}$ production rates during heating up the pristine surface in $\mathrm{NH}_{3}+\mathrm{O}_{2}$ and during subsequent temperature programmed experiments when the surface already underwent patterning. The rate data for the pristine surface thus correspond to the PEEM data for Fig. 1 . The catalytic activity in $\mathrm{N}_{2}$ production develops beyond $T \approx 470 \mathrm{~K}$, and in NO production beyond $T \approx 520 \mathrm{~K}$. On the pristine surface the relative rate maxima are higher than on the already patterned surface but on the patterned surfaces $\mathrm{N}_{2}$ production sets in earlier than on the pristine surface. The comparison with the rate curves of the bare $\mathrm{Rh}(111)$ surface reveals that the bare $\mathrm{Rh}(111)$ surface exhibits the highest catalytic activity of all surfaces. The difference in the height of the rate maxima is between a factor of 1.2 and a factor of 2 .

The difference between the experiment with the pristine surface and the subsequent experiments is that the starting point of the pristine surface is a $\mathrm{Rh}(111)$ surface uniformly covered with $\mathrm{VO}_{x}$ whereas for the subsequent rate curves the starting point is a surface consisting already of macroscopic

$\ddagger$ Due to final state effects in thin $\mathrm{VO}_{\mathrm{x}}$ layers the assignment of the $\mathrm{V} 2 \mathrm{p}_{3 / 2}$ binding energies to different oxidation states of $\mathrm{V}$ in ref. 19 should be considered as tentative. 



Fig. 1 PEEM images demonstrating the development of a stripe pattern and of circular $\mathrm{VO}_{x}$ islands during ammonia oxidation in a temperature programmed experiment. After preparation the sample is slowly heated up in an atmosphere of $\mathrm{NH}_{3}$ and $\mathrm{O}_{2}$ (heating rate $=0.5 \mathrm{~K} \mathrm{~s}^{-1}$ ). Experimental conditions: $\theta_{\mathrm{V}}=0.2 \mathrm{MLE}, p\left(\mathrm{NH}_{3}\right)=3 \times 10^{-4} \mathrm{mbar}, p\left(\mathrm{O}_{2}\right)=1 \times 10^{-4} \mathrm{mbar}$.

regions of bare metal surface and of the $\mathrm{VO}_{x}$ covered surface. From the amount of deposited vanadium which is with $\theta_{\mathrm{V}}=0.2$ MLE about half of the ideal coverage of the $(\sqrt{ } 7 \times \sqrt{ } 7) R 19.1^{\circ}$ structure one can estimate that more than $50 \%$ of the surface should be a bare metal surface and the other part should be covered with $\mathrm{VO}_{x}{ }^{12,13}$ The red and blue rate curves of $\mathrm{N}_{2}$ production in Fig. 3 clearly reveal the presence of at least two contributions. If we assign the first peak to the bare metal surface then the second peak should mostly represent the $\mathrm{N}_{2}$ formed on the $\mathrm{VO}_{x}$ layer.

In catalytic methanol oxidation we observed a strong increase in formaldehyde production with the onset of pattern formation in the system. ${ }^{19}$ Fig. 4 displays in two plots the coarsening of the stripe pattern in the temperature programmed experiment with ammonia oxidation. The wavelength $v s$. temperature plot in Fig. $4 \mathrm{~b}$ shows that the coarsening of the stripe patterns proceeds in a temperature range from about $820-880 \mathrm{~K}$. Above $880 \mathrm{~K}$ the wavelength remains constant at $\approx 50 \mu \mathrm{m}$. This coarsening process is also visible in intensity cross sections taken perpendicular to the direction of the stripes and which have been stacked on top of each other in Fig. 4a. As one compares the development of the pattern in Fig. 4 with the rate data for the pristine surface in Fig. 3, one realizes that the $\mathrm{N}_{2}$ production already starts to increase far below the onset of pattern formation in between 800 and $820 \mathrm{~K}$ (black curve). However, a connection between restructuring and catalytic activity could be indicated by the NO rate curve because the relative maximum in the NO production rate at $820 \mathrm{~K}$ coincides with the onset of stripe pattern formation in Fig. $4 \mathrm{~b}$. Since the restructuring of the $\mathrm{VO}_{x}$ layer creates structural defects which probably enhance the sticking of oxygen, an increase in oxygen coverage might result which favours NO formation to $\mathrm{N}_{2}$ production.

\section{CO oxidation}

Starting with a uniformly $\mathrm{VO}_{x}$ covered $\mathrm{Rh}(111)$ surface at $300 \mathrm{~K}$, heating up in a reacting gas atmosphere with $p(\mathrm{CO})=$ $3 \times 10^{-4}$ mbar and $p\left(\mathrm{O}_{2}\right)=1 \times 10^{-4}$ mbar to $1020 \mathrm{~K}$ does not lead to pattern formation. Only when the oxygen partial pressure at $T=1020 \mathrm{~K}$ is drastically reduced to $p\left(\mathrm{O}_{2}\right)<3 \times$ $10^{-5}$ mbar the development of a stripe pattern is observed as demonstrated by Fig. 5 . Remarkably, the $\mathrm{VO}_{x}$ islands nucleate all over the surface except for an elliptically shaped bright area around an elongated defect. During the first two minutes $\mathrm{VO}_{x}$ islands neither nucleate in the bright area nor do they invade the area from the outside. A few minutes later the bright area has vanished and $\mathrm{VO}_{x}$ islands move inside the former bright area and even surround the elongated defect as demonstrated by the bottom row of PEEM images in Fig. 5 . At this stage of development the elongated defect behaves as an inert object. As observed before in methanol and ammonia oxidation the dark islands which are close to each other move towards each other and coalesce. ${ }^{19}$

In the following experiment starting from the situation depicted in Fig. 5 a large $\mathrm{VO}_{x}$ island $(>500 \mu \mathrm{m})$ was created by increasing $p\left(\mathrm{O}_{2}\right)$ up to $1 \times 10^{-4} \mathrm{mbar}$ followed by a reduction of $p\left(\mathrm{O}_{2}\right)$ down to $1 \times 10^{-7}$ mbar. The reduction in $p\left(\mathrm{O}_{2}\right)$ caused the $\mathrm{VO}_{x}$ island which appeared dark in PEEM after the first step to become bright as depicted in Fig. 6 for $t=0 \mathrm{~s}$. In the following $p\left(\mathrm{O}_{2}\right)$ is increased stepwise and with each step one observes that the initially thin dark boundary layer of the island broadens more until finally the whole $\mathrm{VO}_{x}$ island is transformed into a 

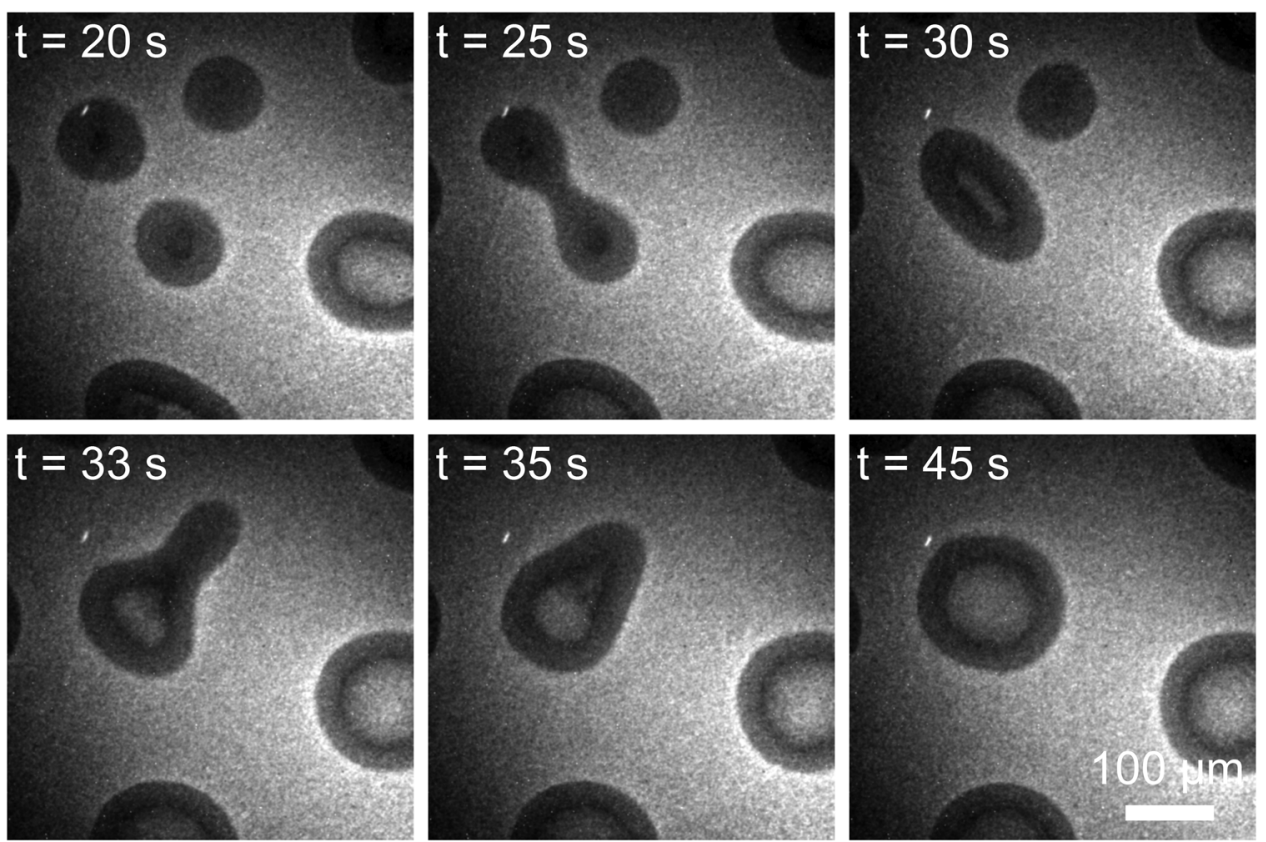

Fig. 2 PEEM images showing the coalescence of $\mathrm{VO}_{x}$ islands under reaction conditions in ammonia oxidation. Experimental conditions: $\theta_{V}=0.2 \mathrm{MLE}$, $T=1020 \mathrm{~K}, p\left(\mathrm{NH}_{3}\right)=3 \times 10^{-4} \mathrm{mbar}$ and $p\left(\mathrm{O}_{2}\right)=1 \times 10^{-4} \mathrm{mbar}$.
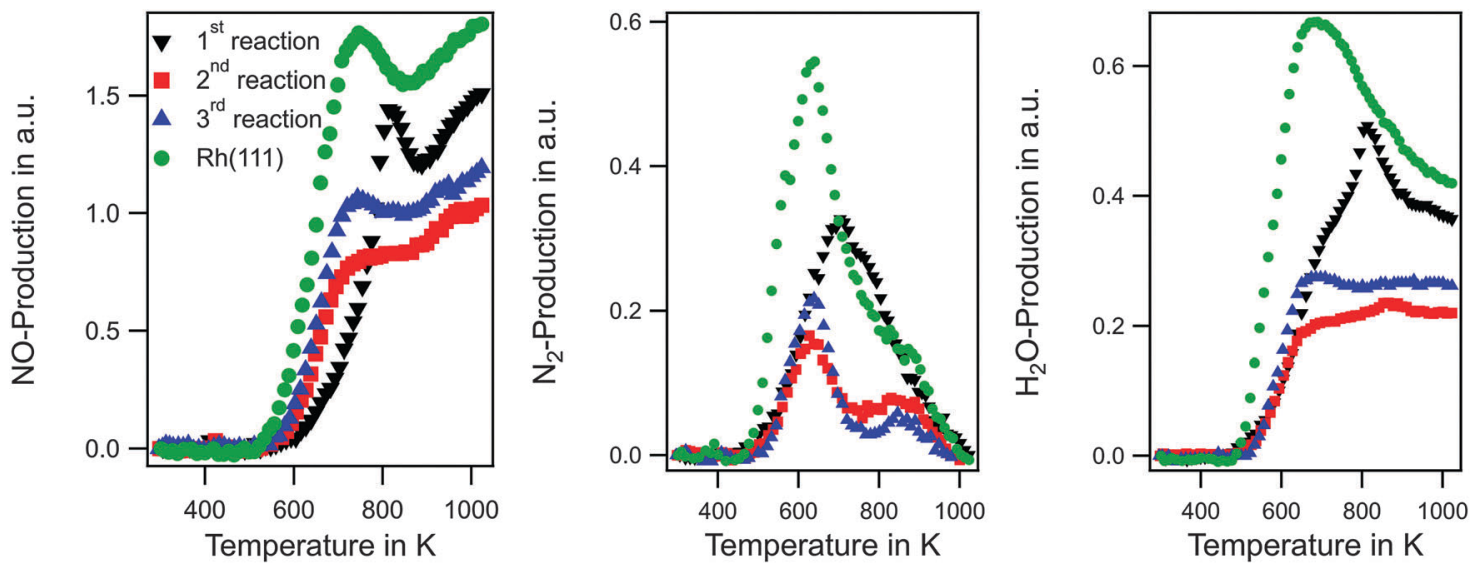

Fig. 3 Evolution of the reaction rates in ammonia oxidation over a $\mathrm{VO}_{x} / \mathrm{Rh}(111)$ catalyst during the temperature programmed experiment displayed in Fig. 1. For comparison the rate curves of the clean Rh(111) surface have been included in the plot (green). The black curves display the rates of the pristine surface, the blue and the red curves display the evolution of the rates in the second and in the third runs, respectively. Experimental conditions: $\theta_{V}=0.2 \mathrm{MLE}, T=350-1000 \mathrm{~K}, \mathrm{p}\left(\mathrm{NH}_{3}\right)=3 \times 10^{-4} \mathrm{mbar}, \mathrm{p}\left(\mathrm{O}_{2}\right)=1 \times 10^{-4} \mathrm{mbar}$, heating rate $=0.5 \mathrm{~K} \mathrm{~s}^{-1}$.

dark area. Using the $\mu$ XPS results from methanol oxidation we can again assign the bright $\mathrm{VO}_{x}$ to a more reduced state of vanadium, e.g. $\mathrm{V}^{3+}$, and the dark $\mathrm{VO}_{x}$ to a more oxidized state, e.g. $\mathrm{V}^{4+} / \mathrm{V}^{5+} \cdot{ }^{5}$ The broadening of the dark boundary layer in Fig. 6 accordingly represents the reoxidation of the reduced $\mathrm{VO}_{x}$ catalyst by the diffusive inflow of adsorbed oxygen from the surrounding metal surface.

\section{Experiments in a pure $\mathrm{O}_{2}$ atmosphere}

At $300 \mathrm{~K} \mathrm{VO}_{x}$ on $\mathrm{Rh}(111)$ exhibits a whole zoo of differently ordered 2D-phases which have been thoroughly characterized by the group of Netzer. ${ }^{12-16}$ At $T \approx 1000 \mathrm{~K}$, however, most of these ordered structures have vanished in LEED due to thermal disorder.
When we prepare large $\mathrm{VO}_{x}$ islands in catalytic $\mathrm{CO}$ oxidation at $T=1020 \mathrm{~K}$ which appear bright in PEEM, we obtain the reduced phase of $\mathrm{VO}_{x}$, i.e. presumably the same phase we see in catalytic methanol oxidation with a large excess of methanol. After cooling down to $300 \mathrm{~K}$, LEED displays a $(2 \times 2)$ pattern and, in addition, as shown by Fig. $7 \mathrm{~b}$ some satellite spots appear around the integer order beams of $\mathrm{Rh}(111)$. This $(2 \times 2)$ is, however, not the wellknown $(2 \times 2)$ of chemisorbed oxygen on $\mathrm{Rh}(111)$ as it becomes evident from a comparison of the thermal stability of both structures shown in Fig. 7a. The intensity of the $(2 \times 2)$ spots of $\mathrm{O} / \mathrm{Rh}(111)$ (red curve) vanishes in a reversible order-disorder transition already below $400 \mathrm{~K}$ even in the presence of oxygen at $p\left(\mathrm{O}_{2}\right)=2 \times 10^{-7}$ mbar. Quite contrarily, the $(2 \times 2)$ of the reduced 

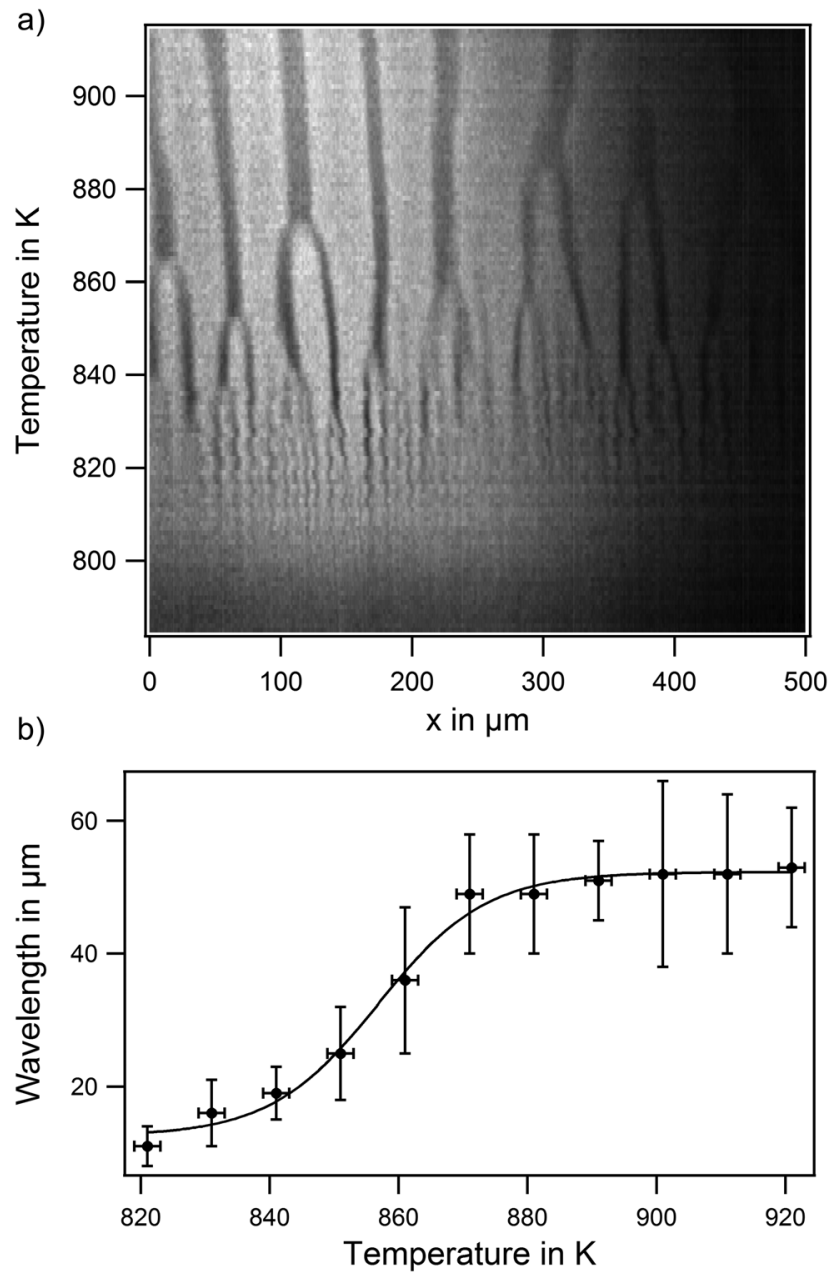

Fig. 4 Coarsening of the stripe pattern in ammonia oxidation over a $\mathrm{VO}_{x} / \mathrm{Rh}(111)$ catalyst during the temperature programmed experiment displayed in Fig. 1. (a) Stacked intensity profiles through the PEEM images displayed in Fig. 1. The vertical axis represents the temperature, and the horizontal axis the position in the intensity profile. (b) Wavelength of the stripe pattern as a function of temperature. Experimental conditions: $\theta_{\mathrm{V}}=0.2 \mathrm{MLE}, T=1020 \mathrm{~K}, p\left(\mathrm{NH}_{3}\right)=3 \times 10^{-4} \mathrm{mbar}, p\left(\mathrm{O}_{2}\right)=1 \times 10^{-4} \mathrm{mbar}$, heating rate $=0.5 \mathrm{~K} \mathrm{~s}^{-1}$.

$\mathrm{VO}_{x}$ phase (black curve) persists up to $800 \mathrm{~K}$ in pure $\mathrm{O}_{2}$. The $(2 \times 2)$-O structure of $\mathrm{O} / \mathrm{Rh}(111)$ is present directly after deposition

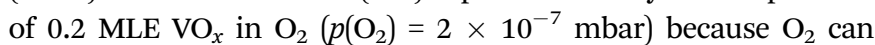
adsorb on those parts of the metal surface not covered by $\mathrm{VO}_{x}$. A $(2 \times 2)$ has not been observed during the deposition of $\mathrm{VO}_{x}$ on $\mathrm{Rh}(111)$ but this structure developed under reaction conditions in the $\mathrm{O}_{2}+\mathrm{H}_{2}$ reaction on the $\mathrm{VO}_{x}$ covered $\mathrm{Rh}(111)$ surface. ${ }^{18}$

In all reaction systems studied so far the $\mathrm{VO}_{x}$ layer on $\mathrm{Rh}(111)$ exhibits stripe patterns and spot patterns under reaction conditions. So far no satisfactory answer has been found for the question about the nature of these patterns. A simple test to see whether reaction conditions are in fact required for generating these structures would be to heat the homogeneously $\mathrm{VO}_{x}$ covered surface obtained after its preparation in pure $\mathrm{O}_{2}$ and follow with PEEM the state of the surface. As demonstrated by the PEEM images in Fig. 8 macroscopic
$\mathrm{VO}_{x}$ islands develop indeed quite similar to the development observed if a catalytic reaction was present. At $T=1020 \mathrm{~K}$ the islands which are of an average diameter of about 50 to $70 \mu \mathrm{m}$ are smaller than the islands formed in catalytic methanol and ammonia oxidation in the $10^{-4}$ mbar range which can reach far more than $200 \mu \mathrm{m}$ size. ${ }^{19}$ The essential difference, however, is that the islands in a pure $\mathrm{O}_{2}$ atmosphere do not move. Over a period of $\approx 1 \mathrm{~h}$ no change in their position is detectable. Evidently the coalescence of $\mathrm{VO}_{x}$ islands requires an on-going catalytic reaction.

The PEEM images in Fig. 8 also show some Ostwald-like ripening as larger islands grow at the expense of smaller ones. This process evidently takes place via evaporation of $\mathrm{small} \mathrm{VO}_{x}$ islands followed by condensation of $\mathrm{VO}_{x}$ clusters at larger islands. The LEED image in Fig. 8 recorded at $300 \mathrm{~K}$ after cooling down in an oxygen atmosphere displays a $(2 \times 2)$ structure that can originate either from chemisorbed oxygen or from the $\mathrm{VO}_{x}$ islands. In addition to the $(2 \times 2)$ pattern some satellite spots also appear around the integer order beams as shown in Fig. 8 (inset). They might originate from the $\mathrm{VO}_{x}$ overlayer or from the oxidized $\mathrm{Rh}(111)$ surface which was shown to exhibit a Moiré type pattern with approximate $(8 \times 8)$ periodicity. ${ }^{21}$

\section{Discussion}

\section{Nature of the $\mathrm{VO}_{x}$ stripe and island patterns}

The nature of the stripe and island patterns that develop in a $\mathrm{VO}_{x}$ layer on $\mathrm{Rh}(111)$ exposed to a catalytic reaction has remained unresolved in earlier studies. If these patterns were a true non-equilibrium structure of Turing type or caused by reactive phase separation then they should form only under reaction conditions and their wavelength should approach a fixed value which is determined by the reaction conditions. ${ }^{22,23}$ Already the first study of the $\mathrm{O}_{2}+\mathrm{H}_{2}$ reaction on $\mathrm{Rh}(111) / \mathrm{VO}_{x}$ demonstrated that the stripe patterns underwent a progressive coarsening within the duration of the experiment (a few hours) without ever approaching asymptotically a stationary value. ${ }^{17,18}$ This practically ruled out the reactive phase separation model which initially was favoured due to the strong chemical interactions which undoubtedly exist in this system.

With the observation that macroscopic $\mathrm{VO}_{x}$ islands already form through annealing in pure $\mathrm{O}_{2}$ a clear answer was found for the above question. The stripe/island patterns are not a nonequilibrium structure in the sense that an on-going reaction is required in order to maintain a situation far from thermodynamic equilibrium.

One can understand the formation of these structures based on purely thermodynamic arguments. After preparation of the $\mathrm{VO}_{x}$ layer the surface looks spatially uniform in PEEM. With regard to the spatial resolution of PEEM which is about $1 \mu \mathrm{m}$ this actually means that the surface is uniform on a macroscale $(>1 \mu \mathrm{m})$. Since the evaporated V coverage of 0.2 MLE is only about half of the ideal $\mathrm{V}$ coverage of the $(\sqrt{ } 7 \times \sqrt{ } 7) R 19.1^{\circ}$ structure which is $\theta_{\mathrm{V}}=0.43 \mathrm{MLE},{ }^{12,13}$ it is clear that on a 

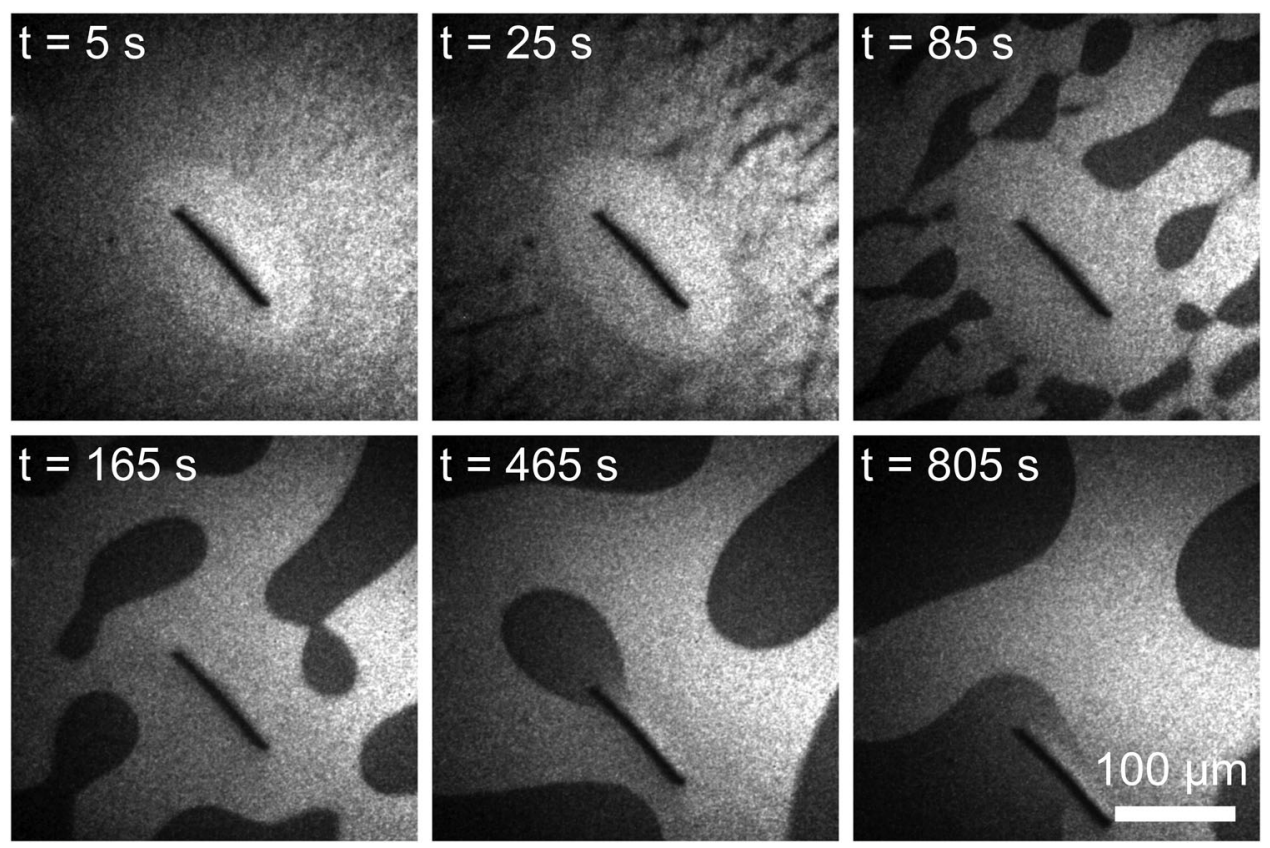

Fig. 5 PEEM images showing the nucleation and coalescence of $\mathrm{VO}_{x}$ islands during catalytic $\mathrm{CO}$ oxidation. The elongated object in the center of the images represents a surface defect. Experimental conditions: $\theta_{\mathrm{V}}=0.2 \mathrm{MLE}, T=1020 \mathrm{~K}, \mathrm{p}(\mathrm{CO})=3 \times 10^{-4} \mathrm{mbar}_{,} \mathrm{p}\left(\mathrm{O}_{2}\right)<0.1 \times 10^{-4} \mathrm{mbar}$.

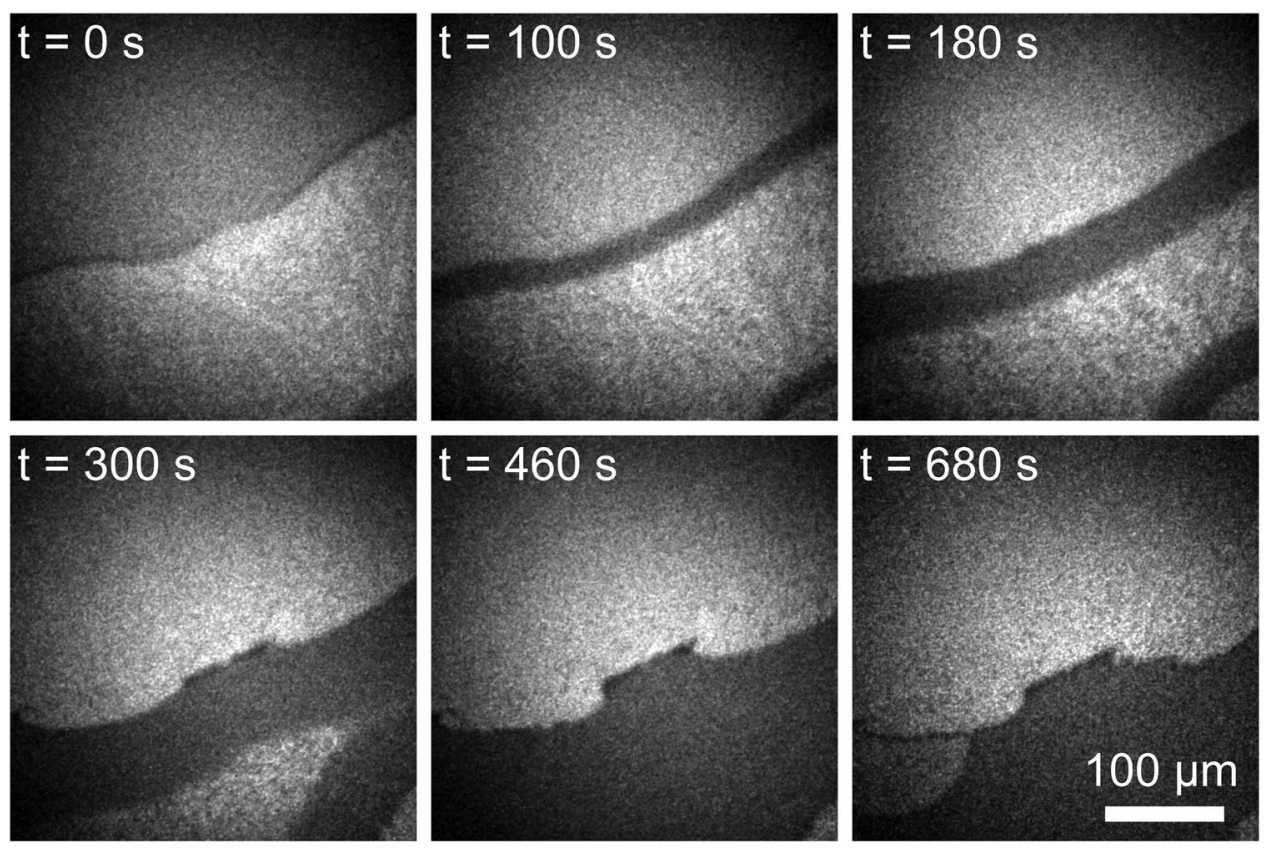

Fig. 6 Formation of an oxidized boundary zone (dark) of a $\mathrm{VO}_{x}$ island showing the progressive reoxidation of the $\mathrm{VO}_{x}$ layer as $p\left(\mathrm{O}_{2}\right)$ is increased stepwise during catalytic $\mathrm{CO}$ oxidation. Experimental conditions: $\theta_{\mathrm{V}}=0.2 \mathrm{MLE}, T=1020 \mathrm{~K}, p(\mathrm{CO})=3 \times 10^{-4} \mathrm{mbar}_{,} p\left(\mathrm{O}_{2}\right)$ is stepwise increased from $5 \times 10^{-7} \mathrm{mbar}$ to $1 \times 10^{-4} \mathrm{mbar}$.

mesoscale the $\mathrm{VO}_{x}$ layer cannot be uniform but has to exhibit a structure which leaves about half of the metal surface uncovered by $\mathrm{VO}_{x}$. With the higher resolving power of low energy electron microscopy (LEEM), in fact, a porous structure of the $\mathrm{VO}_{x}$ layer was revealed with pores of the size of a few tenths of a micrometer. ${ }^{19}$ Due to the very large interfacial region on the $\mathrm{VO}_{x} /$ bare metal surface such a structure is energetically highly unfavourable.
As the $\mathrm{VO}_{x}$ units become mobile upon heating they condense into more compact structures thus getting rid of part of the energetically unfavourable interfacial region. Thermodynamically the most stable state would be to form one very large island but due to limitations in the $\mathrm{VO}_{x}$ mobility this state is unattainable. Instead macroscopic $\mathrm{VO}_{x}$ islands develop which is the situation we see in the PEEM images of Fig. 8. 
a)

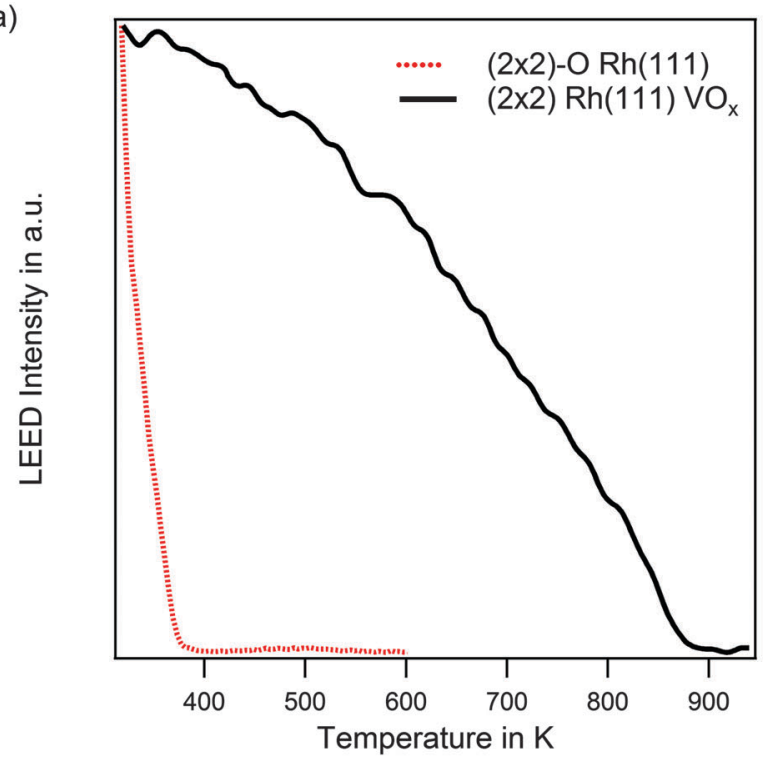

b)



C)



Fig. 7 Thermal stability curves demonstrating the existence of two different $(2 \times 2)$ overlayers. (a) LEED intensity vs. temperature curves of the two half-order beams indicated in (b) and (c) recorded in an oxygen atmosphere with $p\left(\mathrm{O}_{2}\right)=2 \times 10^{-7} \mathrm{mbar}$. (b) $(2 \times 2)$ of $\mathrm{VO}_{x} / \mathrm{Rh}(111)$, at $300 \mathrm{~K}$ (see text) (c) $(2 \times 2)$ - $O$ of $\mathrm{O} / \mathrm{Rh}(111)$ superimposed on the $(\sqrt{ } 7 \times \sqrt{ } 7) R 19.1^{\circ}$ $\mathrm{VO}_{x} / \mathrm{Rh}(111)$ structure at $300 \mathrm{~K}$.

The coarsening process we observe in the stripe pattern after their formation is simply the same process as island ripening in a first order phase transition. The fact that in a catalytic reaction larger $\mathrm{VO}_{x}$ island sizes can be observed than in pure $\mathrm{O}_{2}$ can be attributed to the catalytic reaction enhancing the mobility of the $\mathrm{VO}_{x}$ units.

\section{Coalescence of islands}

The primary motivation for this study has been to verify whether the island coalescence via a polymerization/depolymerization mechanism also holds for other reactions besides methanol oxidation. ${ }^{19}$ This has been confirmed as we see an island coalescence under reaction conditions also in the catalytic oxidation of ammonia and CO. Under comparable conditions, i.e. at $\approx 1000 \mathrm{~K}$ and a pressure in the $10^{-4} \mathrm{mbar}$ range we see more or less the same $\mathrm{VO}_{x}$ island coalescence process in the different reactions. With strongly reduced dynamics a similar island coalescence can also be seen in the $\mathrm{O}_{2}+\mathrm{H}_{2}$ reaction on $\mathrm{Rh}(111) / \mathrm{VO}_{x}$.

The observation that the macroscopic islands formed in pure $\mathrm{O}_{2}$ do not move corroborates the proposed polymerization/depolymerization mechanism because the island movement requires a gradient in the oxygen coverage which can only exist under reaction conditions. In catalytic methanol oxidation the $\mathrm{VO}_{x}$ islands were shown to represent catalytic "micro reactors" thus acting as sinks for oxygen which adsorbs on the surrounding free metal surface and diffuses to the $\mathrm{VO}_{x}$ islands where it feeds the catalytic reaction. Accordingly an oxygen gradient exists around the $\mathrm{VO}_{x}$ islands which is visible in PEEM and which has been measured directly by $\mu$ XPS. ${ }^{19}$ In the PEEM images of Fig. 2 we observe a bright halo around the $\mathrm{VO}_{x}$ islands reflecting a decrease in oxygen coverage. One could accordingly conclude that also in ammonia oxidation the $\mathrm{VO}_{x}$ islands act as sinks for chemisorbed oxygen. However, this conclusion seems to be at variance with the observation that in ammonia oxidation the bare $\mathrm{Rh}(111)$ surface is catalytically more active than a $\mathrm{VO}_{x}$ layer. This contradiction does not necessarily exist if we assume that firstly, the catalytic activity of $\mathrm{VO}_{x}$ though smaller than on $\mathrm{Rh}(111)$ is still substantial and, secondly, that the rate of oxygen adsorption is very small on the $\mathrm{VO}_{x}$ layer. In that case the oxygen needed for ammonia oxidation at the $\mathrm{VO}_{x}$ island still needs to be supplied from the outside which means that an oxygen gradient around the $\mathrm{VO}_{x}$ islands has to exist.

In catalytic $\mathrm{CO}$ oxidation $\mathrm{VO}_{x}$ islands also coalesce as demonstrated by the PEEM images in Fig. 5 but gradients in the oxygen coverage around the islands are difficult to see because of the inhomogeneous illumination of the imaged
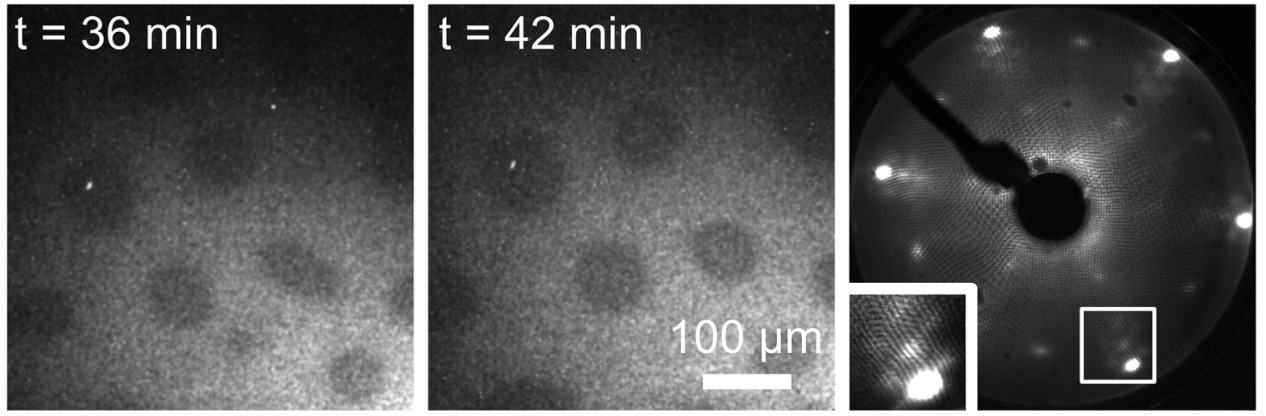

Fig. 8 PEEM images and a LEED pattern demonstrating the formation of macroscopic $V O_{x}$ islands in pure oxygen upon heating. The two PEEM images (left) recorded at $T=1020 \mathrm{~K}$ also show some ripening process as small islands evaporate. After preparation of the $\mathrm{VO}_{x}$ layer the sample was heated in oxygen with a heating rate of $0.5 \mathrm{~K} \mathrm{~s}^{-1}$ up to $T=1020 \mathrm{~K}$. Experimental conditions: $\theta_{\mathrm{V}}=0.2 \mathrm{MLE}, T=1020 \mathrm{~K}, \mathrm{p}\left(\mathrm{O}_{2}\right)=1 \times 10^{-4} \mathrm{mbar}$. The LEED image is recorded at $T=300 \mathrm{~K}$ after cooling the sample down in an oxygen atmosphere. 
area with UV photons. The PEEM images in this figure, however, display a rather remarkable effect. In the center of the image is an elongated defect which impedes the nucleation of $\mathrm{VO}_{x}$ islands in an elliptical bright area around the defect. The effect is only present during the first couple of minutes and then vanishes without a parameter change from outside initiating a different behaviour. The elliptical bright area around the defect looks as if the diffusive spreading of a species originating from the defect would cause some change in the surface properties. Since surface defects very often are known to increase oxygen sticking one could think of the defect acting as an oxygen source. But, firstly, the oxygen sticking on $\mathrm{Rh}(111)$ with $\mathrm{s}\left(\mathrm{O}_{2}\right)$ being around 0.2 (at $100 \mathrm{~K}$ ) is already quite high and, secondly, an increase in the oxygen coverage should cause a darkening of the area and not a brightening as it is observed here. ${ }^{24,25}$

If instead one assumes that the defect is an effective source for $\mathrm{CO}$ then the reactive removal of chemisorbed oxygen by $\mathrm{CO}$ would be consistent with the bright area around the defect. Then one still needs to explain why a low oxygen coverage impedes the nucleation of $\mathrm{VO}_{x}$ islands. In an earlier study of the $\mathrm{O}_{2}+\mathrm{H}_{2}$ reaction on $\mathrm{Rh}(111) / \mathrm{VO}_{x}$ it was concluded that chemisorbed oxygen acts as kind of surfactant for $\mathrm{VO}_{x}$ reducing the line tension between a $\mathrm{VO}_{x}$ island and the surrounding bare metal surface. ${ }^{17,18}$ If we assume that chemisorbed oxygen stabilizes the free $\mathrm{V}_{n} \mathrm{O}_{m}$ clusters on the bare metal surface then in turn a reduced oxygen coverage would have a low concentration of free V-clusters as consequence. This could explain why no nucleation of $\mathrm{VO}_{x}$ islands is seen in the bright elliptical area.

A second point which needs to be explained is why the defect, without further parameter change, loses its ability of preventing the nucleation of $\mathrm{VO}_{x}$ islands in its neighbourhood. After a few minutes the defect behaves as an inert material and $\mathrm{VO}_{x}$ islands flow around it (frame at $t=465 \mathrm{~s}$ in Fig. 5). One possible explanation is that the catalytic reaction has modified the properties of the defect so that it no longer acts as a source for adsorbed CO. An alternative rationalization would be that the bright zone around the defect is the result of a contamination, for example, by adsorbed carbon. As the contamination in the course of the reaction is reactively removed, the bright area returns to its normal properties. Both explanations, the defect as a CO source and the contamination zone, are in agreement with experimental observations and should be considered as realistic.

\section{Reoxidation of the $\mathrm{VO}_{\boldsymbol{x}}$ layer}

Reoxidation of $\mathrm{VO}_{x}$ which becomes reduced in the course of a catalytic partial oxidation reaction is an essential part of a catalytic cycle of a $\mathrm{VO}_{x}$ catalyst. In a recent study of the reoxidation process of $\mathrm{VO}_{x}$ on a $\gamma-\mathrm{Al}_{2} \mathrm{O}_{3}$ support it was shown that the reoxidation process is mechanistically highly complex and that even very small amounts of water can have a decisive influence on the kinetics of this process. ${ }^{7}$ With $\gamma-\mathrm{Al}_{2} \mathrm{O}_{3}$ as a support material the oxygen needed for oxidation can only be supplied via the gas-phase. With $\mathrm{VO}_{x}$ on $\mathrm{Rh}(111)$ a second pathway opens. The initial oxygen sticking coefficient on $\mathrm{Rh}(111)$ of 0.2 is already high which is estimated one to two orders of magnitude higher than the oxygen sticking coefficient over the $\mathrm{VO}_{x}$ layer. ${ }^{24}$ Oxygen can therefore adsorb onto the metal surface, diffuse to the $\mathrm{VO}_{x}$ layer and after diffusing into the interior of the $\mathrm{VO}_{x}$ layer oxygen atoms are incorporated into the catalyst. The dark zones around the $\mathrm{VO}_{x}$ islands we observe in PEEM images demonstrate that this reoxidation process via surface diffusion actually takes place. The substructure we observe in PEEM images of the $\mathrm{VO}_{x}$ islands in ammonia oxidation (Fig. 2) and in methanol oxidation is evidently a consequence of the diffusive transport of oxygen from the boundary into the interior of the islands. ${ }^{19}$ By simulating the experimental data with a realistic mathematical model it should be possible to extract values for the diffusion constant of oxygen on the $\mathrm{VO}_{x}$ layer. Such a modeling with more detailed experimental data is planned for the future.

\section{Conclusions}

A $\mathrm{Rh}(111)$ surface covered with submonolayer quantities of $\mathrm{V}$ oxide was studied as a model catalyst in the catalytic oxidation of ammonia and carbon monoxide. In both reaction systems the initially spatially uniform $\mathrm{VO}_{x}$ film condenses under reaction conditions upon heating into a macroscopic stripe pattern which at elevated temperatures transforms into a spot pattern of circular $\mathrm{VO}_{x}$ islands. Under reaction conditions at $T \approx 1000 \mathrm{~K}$ the islands coalesce thus showing a similar island ripening process as observed earlier with catalytic methanol oxidation on $\mathrm{Rh}(111) / \mathrm{VO}_{x}{ }^{18}$ Evidently, the coalescence of $\mathrm{VO}_{x}$ islands under reaction conditions is a rather robust process since it has been observed in several different reaction systems.

Since heating a $\mathrm{Rh}(111)$ surface partially covered with $\mathrm{VO}_{x}$ in pure oxygen is sufficient to generate macroscopic stripe and spot patterns of condensed $\mathrm{VO}_{x}$ these patterns do not represent a true non-equilibrium structure in the sense that an on-going reaction is required for their formation. Most likely it is just the reduction in interfacial energy between the free metal surface and the $\mathrm{VO}_{x}$ covered metal surface which is driving the condensation of the $\mathrm{VO}_{x}$ layer in a porous network structure into macroscopic stripes and islands.

Under reaction conditions $\mathrm{VO}_{x}$ islands beyond a size of about $40 \mu \mathrm{m}$ exhibit a substructure in PEEM with a bright core and a dark outer ring. In catalytic $\mathrm{CO}$ oxidation this dark outer ring was shown to broaden with increasing $p\left(\mathrm{O}_{2}\right)$. This demonstrates that the oxygen which in a catalytic cycle is needed for reoxidation of the partially reduced $\mathrm{V}$ oxide is supplied by surface diffusion from the surrounding metal surface and not by direct adsorption from the gas-phase. In contrast, the reducing species $\left(\mathrm{CH}_{3} \mathrm{OH}, \mathrm{NH}_{3}\right.$ or $\left.\mathrm{CO}\right)$ adsorbs directly from the gas-phase onto the $\mathrm{VO}_{x}$ island and reacts there.

The results obtained here show that the island coalescence mechanism is quite robust and not restricted to catalytic methanol oxidation alone. Moreover, an island coalescence mechanism could not only play a role for supported $\mathrm{VO}_{x}$ but the same process could also take place in other supported oxide catalysts which exhibit a similar network structure as $\mathrm{VO}_{x}$ on $\mathrm{Rh}(111)$. 


\section{Notes and references}

1 G. C. Bond and S. F. Tahir, Appl. Catal., 1991, 71, 1-31.

2 I. E. Wachs, Catalysis, 1997, 13, 37-54.

3 G. Deo and I. E. Wachs, J. Catal., 1994, 146, 323-334.

4 J. Döbler, M. Pritzsche and J. Sauer, J. Am. Chem. Soc., 2005, 127, 10861-10868.

5 A. Goodrow and A. T. Bell, J. Phys. Chem. C, 2007, 111, 14753-14761.

6 Y. Romanyshyn, S. Guimond, H. Kuhlenbeck, S. Kaya, R. P. Blum, H. Niehus, S. Shaikhutdinov, V. Simic-Milosevic, N. Nilius, H.-J. Freund, M. V. Ganduglia-Pirovano, R. Fortrie, J. Döbler and J. Sauer, Top. Catal., 2008, 50, 106.

7 B. Frank, R. Fortrie, C. Hess, R. Schlögl and R. Schomäcker, Appl. Catal., A, 2009, 353, 288-295.

8 M. V. Ganduglia-Pirovano, C. Popa, J. Sauer, H. Abbott, A. Uhl, M. Baron, D. Stacchiola, O. Bondarchuk, S. Shaikhutdinov and H.-J. Freund, J. Am. Chem. Soc., 2010, 132, 2345-2349.

9 G. S. Wong, D. D. Krayten and J. M. Vohs, J. Phys. Chem. B, 2001, 105, 1366-1373.

10 J. M. Sturm, D. Göbke, H. Kuhlenbeck, J. Döbler, U. Reinhardt, M. V. Ganduglia-Pirovano, J. Sauer and H.-J. Freund, Phys. Chem. Chem. Phys., 2009, 11, 3290-3299.

11 D. Göbke, Y. Romanyshyn, S. Guimond, J. M. Sturm, H. Kuhlenbeck, J. Döbler, U. Reinhardt, M. V. GandugliaPirovano, J. Sauer and H.-J. Freund, Angew. Chem., Int. Ed., 2009, 48, 3695-3698.

12 J. Schoiswohl, M. Sock, S. Eck, S. Surnev, M. G. Ramsey, F. P. Netzer and G. Kresse, Phys. Rev. B: Condens. Matter Mater. Phys., 2004, 69, 155403.
13 J. Schoiswohl, S. Surnev, M. Sock, S. Eck, M. G. Ramsey, F. P. Netzer and G. Kresse, Phys. Rev. B: Condens. Matter Mater. Phys., 2005, 71, 165437.

14 J. Schoiswohl, G. Kresse, S. Surnev, M. Sock, M. G. Ramsey and F. P. Netzer, Phys. Rev. Lett., 2004, 92, 206103.

15 J. Schoiswohl, S. Surnev, M. Sock, M. G. Ramsey, G. Kresse and F. P. Netzer, Angew. Chem., Int. Ed., 2004, 43, 5546-5549.

16 S. Surnev, A. Fortunelli and F. P. Netzer, Chem. Rev., 2012, 113, 4314-4372.

17 F. Lovis, M. Hesse and R. Imbihl, Catal. Lett., 2010, 136, 171-176.

18 F. Lovis and R. Imbihl, J. Phys. Chem. C, 2011, 115, 19141-19148.

19 M. Hesse, B. von Boehn, A. Locatelli, A. Sala, T. O. Menteş and R. Imbihl, Phys. Rev. Lett., 2015, 115, 136102.

20 H. H. Rotermund, Surf. Sci. Rep., 1997, 29, 265-364.

21 J. Gustafson, A. Mikkelsen, M. Borg, E. Lundgren, L. Köhler, G. Kresse, M. Schmid, P. Varga, J. Yuhara, X. Torrelles, C. Quirós and J. N. Andersen, Phys. Rev. Lett., 2004, 92, 126102.

22 Y. De Decker, H. Marbach, M. Hinz, S. Günther, M. Kiskinova, A. S. Mikhailov and R. Imbihl, Phys. Rev. Lett., 2004, 92, 198305.

23 Y. De Decker and A. S. Mikhailov, J. Phys. Chem. B, 2004, 108, 14759-14765.

24 P. A. Thiel, J. T. Yates Jr. and W. H. Weinberg, Surf. Sci., 1979, 82, 22-44.

25 K. A. Peterlinz and S. J. Sibener, J. Phys. Chem., 1995, 99, 2817-2825. 